\title{
Urgences
}

\section{Vertigineusement anglaise, P.D. James, nouvelle reine du crime \\ Phyllis Dorothy James, La proie pour l'ombre, Paris, Fayard, 1984.}

\section{Hélène Chassé}

Numéro 24, juillet 1989

Le manuscrit sous l'angle

URI : https://id.erudit.org/iderudit/025538ar

DOI : https://doi.org/10.7202/025538ar

Aller au sommaire du numéro

Éditeur(s)

Urgences

ISSN

0226-9554 (imprimé)

1927-3924 (numérique)

Découvrir la revue

Citer ce compte rendu

Chassé, H. (1989). Compte rendu de [Vertigineusement anglaise, P.D. James, nouvelle reine du crime / Phyllis Dorothy James, La proie pour l'ombre, Paris, Fayard, 1984.] Urgences, (24), 114-115. https://doi.org/10.7202/025538ar d'utilisation que vous pouvez consulter en ligne.

https://apropos.erudit.org/fr/usagers/politique-dutilisation/ 


\section{deliveline}

\section{VERTIGINEUSEMENT ANGLAISE P.D. James}

\section{NOUVELLE REINE DU CRIME}

Jamais deux initiales d'un prénom n'ont fait autant courir les férus de littérature policière. Des millions de lecteurs à travers le monde, maintenant inconditionnels, en demandent plus que l'auteure peut en fournir. Mine d'or pour les éditeurstraducteurs qui monnaient des parutions vieilles de quinze ans qu'ils maquillent en «nouveautés"...

Syndrome du succès à la John Irving où, en français du moins, toute tentative de lecture chronologique de loeuvre du romancier se transforme en cauchemar

Phyllis Dorothy James est née à Oxford en 1920, l'année même où Agatha Christie, sa célèbre devancière, publiait son premier récit: $L a$ mystérieuse affaire de Styles. Croire que l'aînée a tracé la voie à la cadette serait une erreur. P.D. James n'a rien d'une lady rebelle et dilettante, et aucun de ses romans n'est charmant.

Quand à 50 ans, elle décida d'abandonner son métier pour se consacrer exclusivement à l'écriture, elle rendait utile le cadeau de sa propre expérience. N'avait-elle pas travaillé toute sa vie à la section crimi- nelle du Home Office et ne dirigeaitelle pas un des plus importants laboratoires médico-légal de Londres? Du même coup, elle se préservait des contacts permanents avec ses amis scientistes de Scotland Yard et s'assurait de pouvoir mêler à sa mémoire et à son imagination des faits récents et des précisions techniques (souvent macabres) d'une rare modernité.

La venue de P.D. James à l'écriture de polars n'a donc rien de fortuit. Elle savait la tension qui a toujours existé entre le genre et l'oeuvre, elle connaissait les jeux et les secrets dangereux qui font les intrigues de grand cru et, surtout, femme érudite et passionnée de littérature, elle voulait vivre d'une plume qui lui chatouillait les doigts. An unsuitable job for a woman (La proie pour l'ombre) parut chez Faber and Faber en 1972.

\section{Un certain goût pour la mort}

D'aucuns peuvent regarder sans nausée,

Moi, je n'ai jamais acquis cette faculté.

Le sang et l'haleine ont ceci de particulier

Qu'ils donnent à I'homme un certain goût pour la mort.

Extraite d'un poème de A.E. Housman, mise en épigraphe par l'auteure dans le roman du même nom (1986 - jusqu'ici son chef-d'oeuvre) cette expression est la clé permettant aux lecteurs de saisir l'attirant de l'effarement et de la répulsion, sourire sarcastique en sus, et de jouir de ce que P.D. James apporte de "nouveau" dans un genre qui s'est payé le "sérieux" des cerveaux-ordinateurs 
et des petites cellules grises en ébullition dans de vieux corps usés.

Nous lirions la plupart des romans de P.D. James même si la fin manquait. Car au-delà des éléments du suspense, dosés avec habilité, le surpassement est ailleurs: dans le portrait des personnages, la description des lieux (à la symétrie brisée), l'analyse féroce et subtile des haines, des jalousies, des atmosphères irrespirables, la dénonciation (mine de rien) des mentalités britanniques actuelles, et - oh! "efficacité remarquable" - cet humour qui ne se dément jamais même dans les scènes les plus naturalistes!... «Seuls mes personnages les plus déplaisants sont imaginaires..." s'amuse à répéter P.D. James.

\section{Adam Dalgliesh}

Ne pas en parler serait trahir la romancière. C'est dans ce héros fin limier qu'elle déploie son talent diabolique et son plus grand raffinement.

Chef de police peu ordinaire, Dalgliesh, dans la quarantaine, ne traîne pas seulement avec lui un passé douloureux. Il est poète que l'on publie, amateur d'architecture et fervent de musique baroque. Là encore n'est pas le plus étonnant. Sherlock Holmes, qui enfumait peut-être son insensibilité par l'opium, jouait très bien du violon!

La connaissance de l'angoisse et de l'horreur exerce sur Dalgliesh une fascination tellement ambiguë qu'il séduit et déconcerte.

Personnage non conformiste il est lui seul, avec une affectueuse dérision de la part de l'auteure, tout ce que les autres enquêteurs de Scotland Yard ne devraient jamais être: flegmatique angoissé, raisonneur intuitif et sensible orgueilleux. Ni le pouvoir dont il dispose, ni les succès qu'il remporte n'ont pu, jusqu'à maintenant, l'éloigner de son insaissable besoin de discrétion et de solitude. Les réponses, il les trouve strictement en lui-même.

A côté d'Adam Dalgliesh, Cordélia Gray (la jeune détective des romans les moins forts de P.D. James), malgré une bravoure énergique et le fait qu'elle aime approcher les menaces de trop près, fait figure d'esquisse médiocre. A moins qu'un jour P.D. James la confronte aux femmes secrètes, dures à la tâche, aguerries à la souffrance qui parsèment son oeuvre ou que Dalgliesh l'entraîne dans le sillon de sa maturité et de sa différence...

\section{Hélène Chassé}

Romans de P.D. James (disponibles en français)

Formats poche:

La proie pour l'ombre - Meurtre dans un fauteuil - La meurtrière - L'ile des morts - Un certain goút pour la mort.

Grands formats:

Sans les mains - Une folie meurtrlère - Meurtres en blouse blanche et (juillet 1989) Mort d'un expert (tous edites chez Fayard, Paris). 